\title{
Asymmetric contests with liquidity constraints
}

\author{
Dietl, Helmut ; Grossmann, Martin
}

\begin{abstract}
We consider two bidders with asymmetric valuations competing to win an exogenous prize. Capital markets are imperfect, such that the contestants possibly face a liquidity constraint. We show that aggregate investments are lower if at least one bidder has a liquidity constraint, even if the lowvaluation bidder possibly increases his/her investments. Furthermore, the effect of the high-valuation bidder's liquidity constraint on competitive balance is ambiguous. However, if the low-valuation bidder is constrained, greater wealth unambiguously increases competitive balance. Surprisingly, if the lowvaluation bidder has a constraint, a tighter constraint can increase his/her profit.
\end{abstract}

DOI: https://doi.org/10.1007/s11127-010-9724-4

Posted at the Zurich Open Repository and Archive, University of Zurich ZORA URL: https://doi.org/10.5167/uzh-54520

Journal Article

Published Version

Originally published at:

Dietl, Helmut; Grossmann, Martin (2012). Asymmetric contests with liquidity constraints. Public Choice, 150(3-4):691-713.

DOI: https://doi.org/10.1007/s11127-010-9724-4 


\title{
Asymmetric contests with liquidity constraints
}

\author{
Martin Grossmann · Helmut Dietl
}

Received: 6 January 2010 / Accepted: 27 September 2010 / Published online: 14 October 2010

(C) Springer Science+Business Media, LLC 2010

\begin{abstract}
We consider two bidders with asymmetric valuations competing to win an exogenous prize. Capital markets are imperfect, such that the contestants possibly face a liquidity constraint. We show that aggregate investments are lower if at least one bidder has a liquidity constraint, even if the low-valuation bidder possibly increases his/her investments. Furthermore, the effect of the high-valuation bidder's liquidity constraint on competitive balance is ambiguous. However, if the low-valuation bidder is constrained, greater wealth unambiguously increases competitive balance. Surprisingly, if the low-valuation bidder has a constraint, a tighter constraint can increase his/her profit.
\end{abstract}

Keywords Asymmetric contests · Competitive balance · Liquidity constraints · Low-valuation bidder · High-valuation bidder

JEL Classification D43 $\cdot \mathrm{D} 72 \cdot \mathrm{C} 72$

\section{Introduction}

In many social and economic situations, agents invest resources to win a prize. Typical applications can be found in patent races, campaigns for political office, lobbying for political rents, firms' competition for market shares, arms races in military conflicts, music competitions, and sports tournaments. Firms, for instance, invest in $R \& D$, the education of their employees, and infrastructure, striving for winning a contest prize. Contestants' willingness to invest is not a sufficient condition for actual investments. Investments crucially depend

M. Grossmann $(\bowtie) \cdot$ H. Dietl

Institute for Strategy and Business Economics, University of Zurich, Zurich, Switzerland

e-mail: martin.grossmann@isu.uzh.ch

H. Dietl

e-mail: helmut.dietl@isu.uzh.ch 
on contestants' liquidity because the availability of financial resources is often limited due to capital market imperfections. ${ }^{1}$

In this paper, we consider two contestants competing to win a prize. Contestants are potentially liquidity-constrained. That is, their maximum investment is limited by their individual wealth. We analyze the impact of liquidity constraints on contestants' (aggregate) investments and on competitive balance. ${ }^{2}$ Liquidity constraints are present in numerous examples. Politicians campaigning for an elective office usually have different budgets. The same holds for firms lobbying for political favors in a rent-seeking contest. In the private sector, firms finance their investments internally or externally. Firms that have retained earnings in the past are less dependent on capital markets. If these markets are imperfect, firms are possibly forced to pass up opportunities for profitable investments due to their respective liquidity situations. In the North American sports leagues, salary caps have been introduced to improve competitive balance. These caps restrict the teams' payroll. Therefore, caps can be interpreted as budget constraints for teams, especially for rich large-market teams that can offer better wages than small-market teams (Késenne 2000: 422).

Liquidity constraints may influence the strategy of bidders. Pitchik and Schotter (1988) show in an experimental study that budget constraints affect bidding behavior in sequential auctions. Bidders try to exploit the constraint of their opponents. On the other hand, liquidity constraints may have important welfare implications. First, politicians with budget constraints lobbying for an elective office or firms with limited access to capital markets seeking a governmental contract may change their investment decisions. This change has a direct effect on rent-dissipation. Second, it is possible that a contestant with a lower prize valuation wins the contest (solely because it has more funds). Therefore, the availability of (financial) resources plays an important role for an efficient investment allocation.

In the literature, contest models with liquidity constraints are considered in different frameworks; Che and Gale (1997) analyse the differences between all-pay auctions and lotteries. They show that total expenditures and rent dissipation are often higher in lotteries than in all-pay auctions if contestants have to consider a budget constraint. In another article, Che and Gale (1998b) analyze caps on political lobbying in an all-pay auction. They conclude that the implementation of caps decreases total surplus and can have the counterintuitive effect of increasing aggregate expenditures. On the other hand, Kaplan and Wettstein (2006) argue that caps are not always fully enforced (e.g., in political competitions and sports). Contestants can exceed caps by incurring a cost. In this case, Kaplan and Wettstein conclude that a cap reduces expected bids but that the welfare of the bidders remains unchanged. Gavious et al. (2002) study an all-pay auction with bid caps and privately informed

\footnotetext{
${ }^{1}$ Imperfect capital markets can arise due to asymmetric information between borrowers and lenders (Hubbard 1998). Other reasons are transaction costs or tax advantages, such that external financing may be more expensive than internal financing (Fazzari et al. 1988a, 1988b; Che and Gale 1998a). Foellmi and Oechslin (2010), for instance, analyze the distributional effects of varied access to external finance.

${ }^{2}$ In the contest literature, different objectives of the contest organizer have been analyzed: one line of research relates the contest organizer's optimal behavior to maximize total expenditures (Che and Gale 1998b; Dasgupta and Nti 1998; Moldovanu and Sela 2001, 2006; Nti 2004). Typical applications are contests, such as sports competitions (where spectators enjoy top performances) and employment tournaments (where firms prefer outstanding efforts of managers). Other research accounts for the further objectives of the contest organizer. Szymanski and Valletti (2005) argue that a contest organizer in sports, for instance, may also try to balance contestants' performances because spectators prefer balanced games. Competitive balance, therefore, fosters the uncertainty of outcome. This is the driver for game attention and the organizer's revenue. Szymanski and Valletti (2005) postulate that competitive balance can also be important in other industries. For instance, governmental institutions organizing research tournaments may also be interested in balanced competitions due to political constraints.
} 
bidders with respect to the prize valuation. ${ }^{3}$ In the case of linear or concave costs, they derive that a cap reduces the average bid. However, in the case of convex costs, the average bid possibly increases depending on the number of bidders and the degree of convexity in the cost functions.

Meirowitz (2008) analyzes the effect of spending limits on candidates' effort choice in political campaigns. He concludes that the introduction of caps results in a game with multiple equilibria. Depending on the selected equilibrium, either the candidate with low effort costs or the candidate with high effort costs has larger expected payoffs. In either equilibrium, candidate payoffs are weakly increasing in the cap. Whereas Meirowitz assumes that candidates have a different fundraising efficiency, Pastine and Pastine (2010a) consider two additional sources of asymmetry: (i) an asymmetry with respect to the candidates' effectiveness in campaign spending and (ii) an asymmetry due to an initial voter disposition advantage. They show that the challenger benefits from a moderate limit under certain preconditions. However, an even more restrictive limit can help the incumbent. The empirical literature derives interesting results of spending limits: Levitt (1994) analyzes 633 elections between 1972 and 1990 in the United States. He finds that spending limits provide a modest advantage for the incumbent. Moreover, Gross et al. (2002) conclude that spending limits reduce the spending of the incumbent and the challenger in gubernatorial elections from 1978 to 1997 in the United States. Using data from 1997 to 2000, Milligan and Rekkas (2008) find that higher spending caps lead to less close races in Canadian federal elections.

In this paper, we consider two asymmetric contestants (who we call the low-valuation and high-valuation bidders) with different prize valuations investing to win an exogenous prize. Simultaneously, a second asymmetry holds the following: investment is limited by the contestant's individual wealth. We analyze contestants' optimal investment behaviors and conclude that there are interesting interaction effects between these two asymmetries. First, if at least one contestant has a liquidity constraint, aggregate investments are unambiguously lower compared to the case without constraints, even if the low-valuation bidder possibly increases his/her investments. Second, the effect of a liquidity constraint on competitive balance depends on the tightness or looseness of this constraint. Consequently, we differentiate between strong and weak liquidity constraints. If the high-valuation bidder has a strong (weak) liquidity constraint and therefore has a winning probability smaller (larger) than $50 \%$ in equilibrium, then greater wealth implies more (less) competitive balance. Otherwise, if the low-valuation bidder has a liquidity constraint, greater wealth unambiguously increases competitive balance. Third, we get the following counterintuitive result in the case of linear investment costs: if the low-valuation bidder has a liquidity constraint, the lowvaluation bidder's payoff may increase as his/her liquidity constraint becomes more binding. The intuition is that both contestants decrease their investments if the low-valuation bidder has less wealth. Therefore, investment externalities and costs decrease, such that the low-valuation bidder's payoff will increase.

In contrast to our model, contest models with liquidity constraints are primarily analyzed in a symmetric context. Che and Gale (1997) consider a contest model where contestants face individual liquidity constraints but have symmetric prize valuations. Che and Gale (1998b), Gavious et al. (2002) as well as Pastine and Pastine (2010b) analyze bidders

\footnotetext{
${ }^{3}$ See also Pai and Vohra (2008) for optimal auctions with privately informed bidders regarding their valuation. They discuss whether budget-constrained bidders should receive subsidies to effectively compete in the auction. According to their model, incentive compatible instruments of subsidy are lump-sum transfers from the auctioneer to the agents. In an optimal auction, however, the auctioneer should never offer subsidies to the agents.
} 
with different prize valuations. However, their models are based on the assumption that contestants have a symmetric cap. ${ }^{4}$ On the other hand, Stein and Rapoport (2005) assume that contestants have symmetric valuations of the prize as well as symmetric budgets. Our setting enables us to fill the gap assuming asymmetric prize valuations as well as asymmetric liquidity constraints. Applications with asymmetric prize valuations in which contestants have individual liquidity constraints are lobbying for political rents, R\&D races for patents, sports competitions, firms' competitions for market shares, and so forth. In all of these examples, contestants usually have different budgets. In addition, contest prizes are valued differently due to individual perceptions or different market potentials. Our analysis provides valuable insights with respect to contestants' investment behaviors and the derivation of welfare implications in these circumstances.

This paper has the following structure: Sect. 2 sets up the model. As a benchmark, we provide an analysis in the case without liquidity constraints in Sect. 3. The results with a minimum of one liquidity constraint are presented in Sect. 4. Section 5 discusses the main findings and provides applications.

\section{Model}

\subsection{Assumptions}

We consider a contest in which contestant $i(i=1,2)$ invests a nonnegative amount $T_{i}$ to increase his/her winning probability for an exogenous prize. The winning probability for contestant $i$ is given by the Tullock contest success function (Tullock 1980): ${ }^{5}$

$$
p_{i}\left(T_{i}, T_{j}\right)=\frac{T_{i}}{T_{i}+T_{j}} \quad \text { for } T_{i}+T_{j}>0
$$

We assume that the winning probability equals zero for each contestant if contestants do not invest, that is, $T_{i}=T_{j}=0$. Furthermore, we assume that contestant 1 values the prize more highly than contestant 2 . Therefore, the prize for contestant 1 is $R_{1}$, and the prize for contestant 2 is $R_{2}$ with $R_{1}>R_{2}>0 .{ }^{6}$ Due to this asymmetry, we henceforth call contestant 1 the "high-valuation bidder" and contestant 2 the "low-valuation bidder". Contestant 1 wins the prize $R_{1}$ with probability $p_{1}\left(T_{1}, T_{2}\right)$ and contestant 2 the prize $R_{2}$ with probability $p_{2}\left(T_{1}, T_{2}\right)=1-p_{1}\left(T_{1}, T_{2}\right)$.

Investment costs $c\left(T_{i}\right)$ are weakly convex. If costs are strictly convex, we assume that $c^{\prime}\left(T_{i}\right)>0$ for $T_{i}>0, c^{\prime}(0)=0$ and $c^{\prime \prime}\left(T_{i}\right)>0$. If costs are linear, then the marginal costs of

\footnotetext{
${ }^{4}$ Che and Gale (1998b) argue that a maximum allowable cap symmetrically holds for each player in political lobbying, motivated by the fact that campaign spending is often limited by law.

${ }^{5}$ Henceforth, $i, j \in\{1,2\}$ and $i \neq j$ if not otherwise quoted. Note that we will often present only contestant $i$ 's result. In this case, contestant $j$ 's result is given by changing subscripts.

${ }^{6}$ In the literature, the contest prize is often the same for each contestant. To achieve some kind of heterogeneity in contest models, contestants differ either in their technology or in a different valuation of the prize. Differences in technology can be based on different productivities, i.e., even if contestants invest identical amounts, the winning probability differs among contestants (Dixit 1987; Nti 1997, 2004; Yildirim 2005). Unequal investment costs of agents are another example for different technologies (Szymanski and Valletti 2005). However, heterogeneity is sometimes modeled assuming different prizes or perceptions of the prize by contestants (Baik and Kim 1997; Che and Gale 1998b). In this paper, we use the latter approach and assume that (the value perception of) the contest prize differs between contestants.
} 
investment are denoted by the constant parameter $\theta$ with $\theta>0$. Fixed costs are normalized to zero for each contestant. The expected payoff of contestant $i$ is denoted by $\pi_{i}:^{7}$

$$
\pi_{i}=\frac{T_{i}}{T_{i}+T_{j}} R_{i}-c\left(T_{i}\right)
$$

We assume that contestants have limited access to capital. Therefore, contestant $i$ 's investment is limited by his/her previously accumulated individual wealth $W_{i}>0$, such that $c\left(T_{i}\right) \leq W_{i}$. If contestant $i$ 's desired investment is larger than his/her wealth, then contestant $i$ is liquidity-constrained. Henceforth, a liquidity constraint means that this constraint strictly binds. We assume that contestants are expected payoff maximizers. Moreover, individual wealth levels as well as individual prize valuations are common knowledge.

We measure competitive balance (CB) by the ratio of the winning probabilities $p_{1} / p_{2}$. If this ratio gets closer to one, competitive balance increases. Using equation (1), we obtain the following relation for competitive balance:

$$
C B \equiv \frac{p_{1}\left(T_{1}, T_{2}\right)}{p_{2}\left(T_{1}, T_{2}\right)}=\frac{T_{1}}{T_{2}} .
$$

\subsection{Optimality conditions}

Contestant $i$ has the following Lagrangian $\mathcal{L}_{i}=p_{i}\left(T_{i}, T_{j}\right) R_{i}-c\left(T_{i}\right)+\lambda_{i}\left[W_{i}-c\left(T_{i}\right)\right]$ with multiplier $\lambda_{i}$ to maximize expected payoffs. We get the following first-order condition using Kuhn-Tucker:

$$
\begin{aligned}
& \frac{T_{j}}{\left(T_{i}+T_{j}\right)^{2}} R_{i}=\left(1+\lambda_{i}\right) c^{\prime}\left(T_{i}\right), \\
& \quad \text { with } W_{i} \geq c\left(T_{i}\right) .
\end{aligned}
$$

The complementary slackness condition is $\lambda_{i}\left[W_{i}-c\left(T_{i}\right)\right]=0$. Next, two different scenarios are considered. In the subsequent section, we assume that contestants do not face a liquidity constraint. Afterwards, at least one contestant is constrained.

\section{Unconstrained bidders}

In this section, we consider wealthy contestants as a benchmark. Hence, neither of the two contestants is considered to be liquidity-constrained.

\subsection{Reaction functions}

If costs are strictly convex, we get the following implicit reaction function for contestant $i$ (see Fig. 1a):

$$
\frac{T_{j}}{\left(T_{i}+T_{j}\right)^{2}} R_{i}=c^{\prime}\left(T_{i}\right) .
$$

\footnotetext{
${ }^{7}$ In the literature, contestants' payoff functions are sometimes modeled using a more general contest success function $p_{i}\left(T_{i}, T_{j}\right)=h_{i}\left(T_{i}\right) /\left(h_{i}\left(T_{i}\right)+h_{j}\left(T_{j}\right)\right)$ combined with linear costs. We use a reduced form of the contest success function, however, in combination with nonlinear costs. Nti (1997: 45) argues that the two frameworks lead to qualitatively similar results in the case without liquidity constraints.
} 


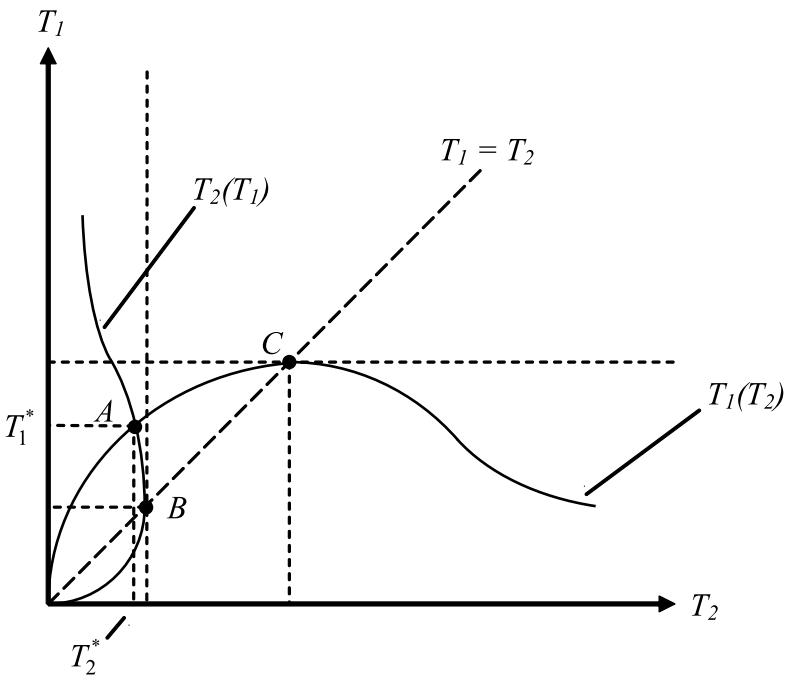

(a)

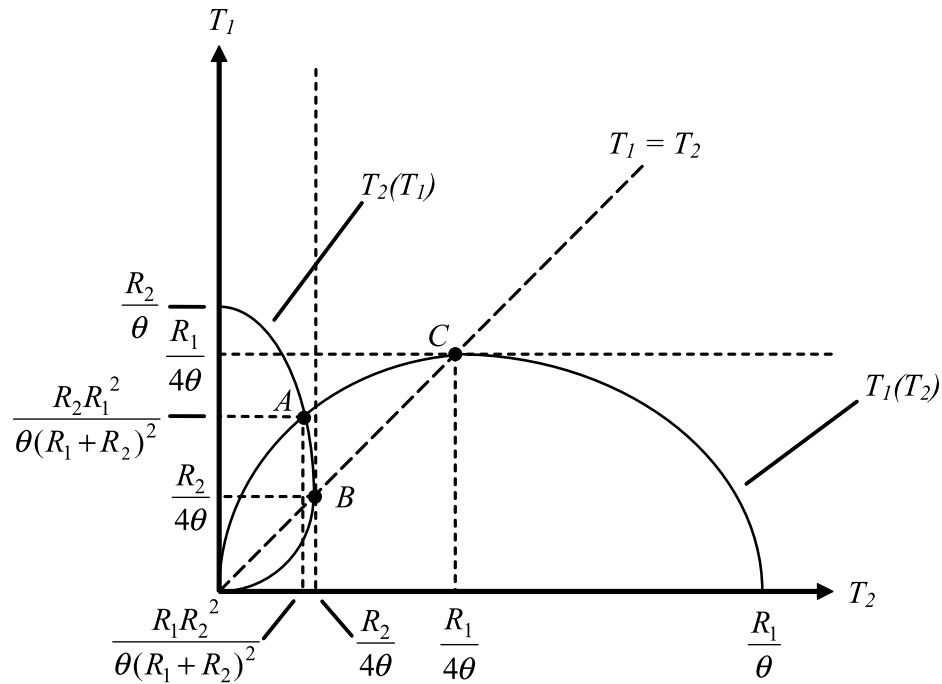

(b)

Fig. 1 a Unconstrained reaction functions with strictly convex costs. b Unconstrained reaction functions with linear costs

Lemma 1 If costs are strictly convex: The reaction function $T_{i}\left(T_{j}\right)$ is strictly concave for $0 \leq T_{i} \leq T_{j} . T_{i}\left(T_{j}\right)$ crosses the $45^{\circ}$-line and achieves its maximum at point $T \equiv T_{i}=T_{j}$, implicitly defined by $R_{i} / 4=c^{\prime}(T) T$. The reaction function has an inflection point defined by $2 R_{i}^{2} T_{i}=R_{i}\left(2 T_{j}-4 T_{i}\right)\left(T_{i}+T_{j}\right)^{2} c^{\prime \prime}\left(T_{i}\right)$ and is convex for high investments of contestant $j$, that is, $R_{i}\left(2 T_{j}-4 T_{i}\right)\left(T_{i}+T_{j}\right)^{2} c^{\prime \prime}\left(T_{i}\right)>2 R_{i}^{2} T_{i}$.

Proof See Appendix 6.1. 
If costs are linear, contestant $i$ has the following reaction function $T_{i}\left(T_{j}\right)$ (see Fig. 1b):

$$
T_{i}\left(T_{j}\right)= \begin{cases}\sqrt{\frac{T_{j} R_{i}}{\theta}}-T_{j} & \text { if } 0 \leq T_{j} \leq \frac{R_{i}}{\theta}, \\ 0 & \text { if } T_{j}>\frac{R_{i}}{\theta}\end{cases}
$$

Lemma 2 sums up the main properties of this reaction function:

Lemma 2 If costs are linear: The reaction function $T_{i}\left(T_{j}\right)$ is strictly concave for $0 \leq$ $T_{j} \leq R_{i} / \theta . T_{i}\left(T_{j}\right)$ crosses the $45^{\circ}$-line and achieves its maximum at point $\left(T_{i}, T_{j}\right)=$ $\left(R_{i} /(4 \theta), R_{i} /(4 \theta)\right)$.

Proof See Appendix 6.2.

\subsection{Equilibrium}

We get the well-known result for linear as well as strictly convex costs in equilibrium: the high-valuation bidder invests more (see point $A$ in Figs. 1a and 1b) and has larger expected payoffs than the low-valuation bidder because the high-valuation bidder has greater marginal revenues (ceteris paribus). ${ }^{8}$

For linear costs, investment $T_{i}^{*}$ and payoff $\pi_{i}^{*}$ for contestant $i$ are as follows:

$$
T_{i}^{*}=\frac{R_{i}^{2} R_{j}}{\left(R_{i}+R_{j}\right)^{2} \theta} \quad \text { and } \quad \pi_{i}^{*}=\frac{R_{i}^{3}}{\left(R_{i}+R_{j}\right)^{2}} .
$$

Note that the explicit derivation of investments and payoffs in equilibrium is only possible in the case of linear costs.

\section{Liquidity constraints}

In the following three subsections, we consider a contest in which one or two contestants are liquidity-constrained. First, we consider a liquidity constraint only for the high-valuation bidder. Second, only the low-valuation bidder is constrained. Finally, both contestants have a liquidity constraint.

\subsection{Liquidity constraint for the high-valuation bidder}

\subsubsection{General cost function}

Suppose that costs are either linear or strictly convex and only the high-valuation bidder is liquidity-constrained. Therefore, point $A$ in Figs. 1a and b cannot be achieved. The tightness of the liquidity constraint determines which contestant invests more in equilibrium (see Figs. 2a and b). If the high-valuation bidder's wealth is relatively large (small), then he/she invests more (less) than the low-valuation bidder.

Therefore, the following definition is introduced:

\footnotetext{
${ }^{8}$ The proof is provided in Appendix 6.3.
} 
Fig. 2 a Weak and strong liquidity constraints for high-val. bidder with strictly convex costs. b Weak and strong liquidity constraints for high-val. bidder with linear costs

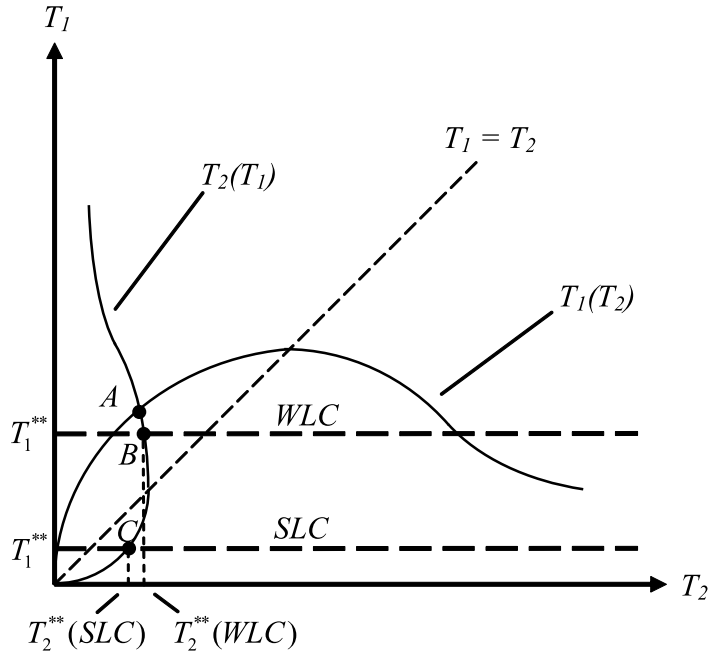

(a)

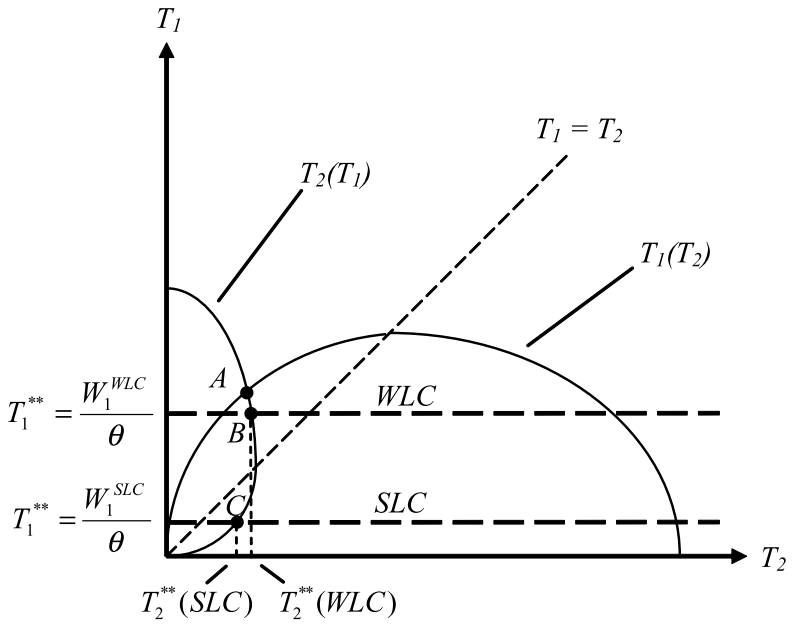

(b)

Definition 1 If the high-valuation bidder is liquidity-constrained but invests more than the low-valuation bidder in equilibrium, then we call this situation a "weak liquidity constraint" (WLC). Otherwise, if the high-valuation bidder is liquidity-constrained and the lowvaluation bidder invests more than the high-valuation bidder in equilibrium, then we use the term "strong liquidity constraint" (SLC). ${ }^{9}$

In equilibrium, we get Proposition 1:

\footnotetext{
${ }^{9}$ See Figs. 2a and b: if there is a WLC, the high-valuation bidder invests more than the low-valuation bidder at equilibrium point $B$. If there is an SLC, the high-valuation bidder invests less than the low-valuation bidder at equilibrium point $C$.
} 
Proposition 1 If only the high-valuation bidder is liquidity-constrained in equilibrium:

(i) Aggregate investments are lower compared to the case without liquidity constraints.

(ii) A strong (weak) liquidity constraint for the high-valuation bidder implies a lesser (greater) winning probability compared to the low-valuation bidder.

(iii) Increasing the high-valuation bidder's wealth leads to more (less) competitive balance if the high-valuation bidder has a strong (weak) liquidity constraint.

Proof See Appendix 6.4.

(i) According to our model, if only the high-valuation bidder is liquidity-constrained, aggregate investments are unambiguously smaller compared to the case without liquidity constraints, even if the low-valuation bidder potentially increases his/her investments. Therefore, the low-valuation bidder's investment increase never compensates for the high-valuation bidder's investment reduction. If the bidders' investments are considered as rent-dissipation, then social welfare increases due to the lower aggregate investment.

(ii) A strong liquidity constraint for the high-valuation bidder implies that it is more likely that the low-valuation bidder wins the contest. This result has important welfare implications because there is an inefficient prize allocation.

(iii) The effect of a relaxation of the high-valuation bidder's liquidity constraint on competitive balance depends on the tightness of the high-valuation bidder's liquidity restriction. If the high-valuation bidder has only a weak liquidity constraint, a higher wealth $W_{1}$ decreases competitive balance, as the high-valuation bidder increases his/her investment and the low-valuation bidder simultaneously decreases his/her investment. Otherwise, if the high-valuation bidder has a strong liquidity constraint, then the high-valuation bidder invests less than the low-valuation bidder. In that case, a higher wealth $W_{1}$ increases the high-valuation bidder's investments as well as those of the low-valuation bidder. However, the high-valuation bidder proportionally increases his/her investments more than the low-valuation bidder, such that competitive balance increases.

\subsubsection{Linear costs}

For linear costs, we get investments ${ }^{10}$

$$
T_{1}^{* *}=\frac{W_{1}}{\theta} \quad \text { and } \quad T_{2}^{* *}=\frac{\sqrt{W_{1}}}{\theta}\left(\sqrt{R_{2}}-\sqrt{W_{1}}\right),
$$

and payoffs ${ }^{11}$

$$
\pi_{1}^{* *}=\frac{\sqrt{W_{1}}}{\sqrt{R_{2}}} R_{1}-W_{1} \text { and } \pi_{2}^{* *}=\left(\sqrt{R_{2}}-\sqrt{W_{1}}\right)^{2}
$$

\footnotetext{
${ }^{10}$ To guarantee a positive investment as well as a non-binding constraint for the low-valuation bidder, we need $\sqrt{R_{2}}>\sqrt{W_{1}}$ as well as $\theta T_{2}^{* *}=\sqrt{W_{1}}\left(\sqrt{R_{2}}-\sqrt{W_{1}}\right) \leq W_{2}$.

${ }^{11}$ The high-valuation bidder's profit is positive if $\pi_{1}^{* *}=R_{1} \sqrt{W_{1}} / \sqrt{R_{2}}-W_{1}>0 \Longleftrightarrow R_{1} \sqrt{R_{2}}>\sqrt{W_{1}} R_{2}$. Because the high-valuation bidder is liquidity-constrained, we know that $R_{1} \sqrt{R_{2}}>\left(R_{1}+R_{2}\right) \sqrt{W_{1}}$. This condition guarantees that the high-valuation bidder's profit is positive. Because the low-valuation bidder has positive investments, we know that $\sqrt{R_{2}}>\sqrt{W_{1}}$, such that $\pi_{2}^{* *}$ is also positive.
} 
in equilibrium. Therefore, whether the high-valuation or the low-valuation bidder has larger investments and payoffs in equilibrium depends on the prizes $R_{1}, R_{2}$ and the high-valuation bidder's wealth $W_{1}$. Note that the high-valuation bidder's liquidity constraint intersects the low-valuation bidder's reaction function exactly on the $45^{\circ}$-line if $2 \sqrt{W_{1}}=\sqrt{R_{2}}$. In that case, contestants invest the same amount in equilibrium. A high $W_{1}$ (such that $2 \sqrt{W_{1}}>$ $\sqrt{R_{2}}$ ) implies that $T_{1}^{* *}>T_{2}^{* *}$, whereas a high $R_{2}$ (such that $2 \sqrt{W_{1}}<\sqrt{R_{2}}$ ) inflates the reaction function $T_{2}\left(T_{1}\right)$ yielding $T_{1}^{* *}<T_{2}^{* *}$ in equilibrium.

Moreover, we are able to provide Proposition 2 for linear costs:

Proposition 2 If only the high-valuation bidder is liquidity-constrained in equilibrium and costs are linear: Increasing the high-valuation bidder's wealth $W_{1}$ leads to larger payoffs for the high-valuation bidder.

\section{Proof See Appendix 6.5.}

According to Proposition 2, relaxing the high-valuation bidder's liquidity constraint increases the high-valuation bidder's payoffs even if the low-valuation bidder's investment possibly increases in equilibrium in the case of linear costs.

\subsection{Liquidity constraint for the low-valuation bidder}

\subsubsection{General cost function}

Suppose that costs are either linear or strictly convex and only the low-valuation bidder is liquidity-constrained. Again, point $A$ in Figs. 1a and b cannot be achieved. Exchanging the contestants' subscripts, the results are analogous to the last subsection, where only the highvaluation bidder is liquidity-constrained. However, we do not get a symmetric proposition (see Figs. 3a and b):

Proposition 3 If only the low-valuation bidder is liquidity-constrained in equilibrium:

(i) Aggregate investments are lower compared to the case without liquidity constraints.

(ii) The high-valuation bidder has a larger winning probability.

(iii) Increasing the low-valuation bidder's wealth $W_{2}$ leads to more competitive balance.

\section{Proof See Appendix 6.6.}

(i) If only the low-valuation bidder is liquidity-constrained, aggregate investments are unambiguously smaller compared to the case without constraints. In contrast to the opposite case, in which only the high-valuation bidder has a constraint, both contestants always decrease their investments. If the bidders' investments are considered to be rentdissipation, then social welfare increases due to the lower aggregate investment.

(ii) According to Figs. $3 a$ and $b$, the equilibrium is always above the 45 -degree line. Therefore, the high-valuation bidder has a larger winning probability in equilibrium.

(iii) A tighter liquidity constraint for the low-valuation bidder, that is, lower wealth $W_{2}$, implies less competitive balance. In contrast to the opposite case, in which only the high-valuation bidder has a constraint (see Proposition 1), this effect is unambiguous. Note that a greater (constrained) wealth of the low-valuation bidder increases the lowvaluation bidder's as well as the high-valuation bidder's investment in equilibrium. However, the low-valuation bidder proportionally increases his/her investment more than the high-valuation bidder, such that competitive balance increases. 
Fig. 3 a Liquidity constraint for low-val. bidder with strictly convex costs. b Liquidity constraint for low-val. bidder with linear costs

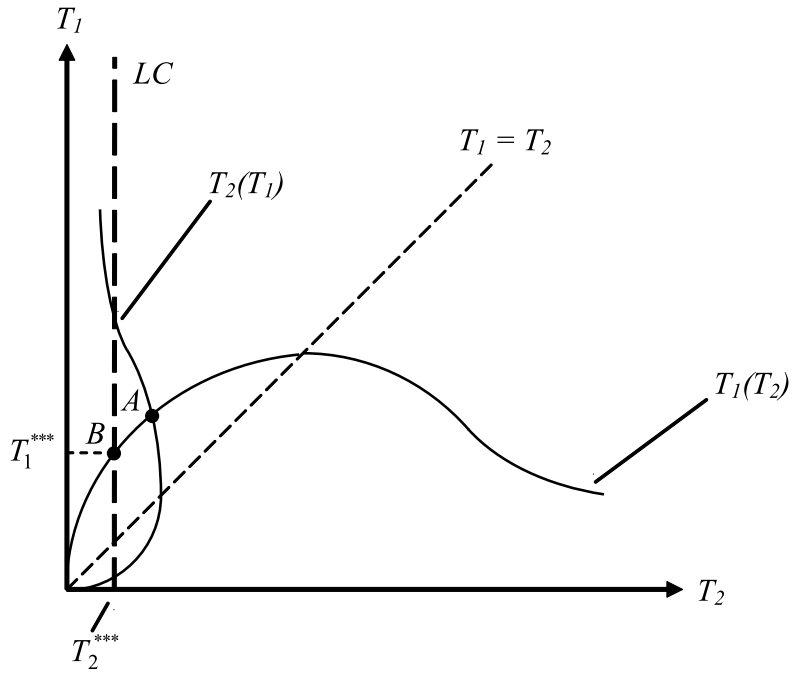

(a)

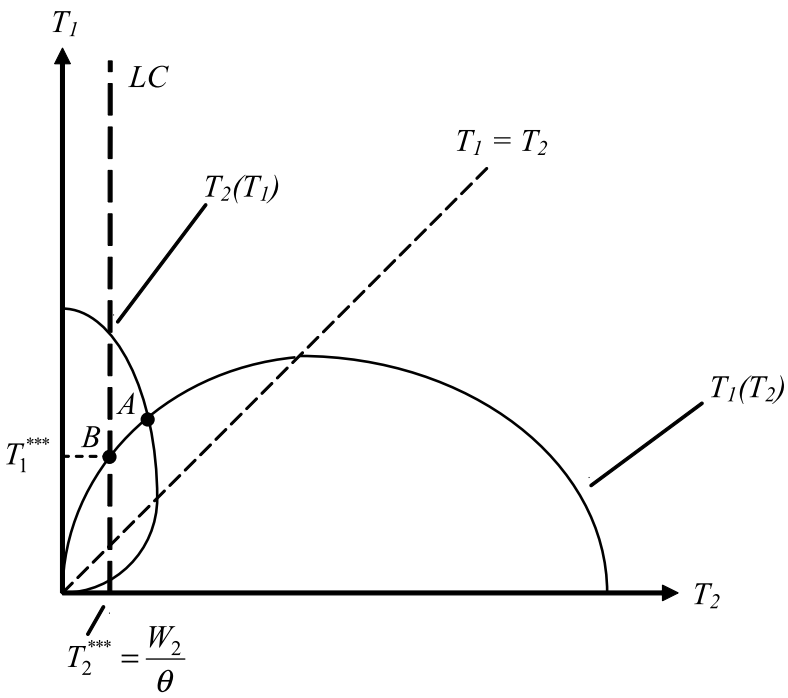

(b)

\subsubsection{Linear costs}

For linear costs, we get investments ${ }^{12}$

$$
T_{1}^{* * *}=\frac{\sqrt{W_{2}}}{\theta}\left(\sqrt{R_{1}}-\sqrt{W_{2}}\right) \quad \text { and } \quad T_{2}^{* * *}=\frac{W_{2}}{\theta},
$$

\footnotetext{
${ }^{12}$ To guarantee a positive investment as well as a non-binding constraint for the high-valuation bidder, we need $\sqrt{R_{1}}>\sqrt{W_{2}}$ as well as $\theta T_{1}^{* * *}=\sqrt{W_{2}}\left(\sqrt{R_{1}}-\sqrt{W_{2}}\right) \leq W_{1}$.
} 
and payoffs ${ }^{13}$

$$
\pi_{1}^{* * *}=\left(\sqrt{R_{1}}-\sqrt{W_{2}}\right)^{2} \text { and } \pi_{2}^{* * *}=\frac{\sqrt{W_{2}}}{\sqrt{R_{1}}} R_{2}-W_{2}
$$

in equilibrium.

Moreover, we are able to provide Proposition 4:

Proposition 4 If only the low-valuation bidder is liquidity-constrained in equilibrium and costs are linear:

(i) Greater wealth $W_{2}$ decreases the high-valuation bidder's payoffs.

(ii) Greater wealth $W_{2}$ increases the low-valuation bidder's payoffs for $R_{2} \sqrt{R_{1}}>$ $2 R_{1} \sqrt{W_{2}}$.

(iii) Greater wealth $W_{2}$ decreases the low-valuation bidder's payoffs for $\sqrt{W_{2}}\left(R_{1}+R_{2}\right)<$ $R_{2} \sqrt{R_{1}}<2 R_{1} \sqrt{W_{2}}$.

Proof See Appendix 6.7.

(i) If the low-valuation bidder is liquidity-constrained and costs are linear, a larger wealth $W_{2}$ decreases the high-valuation bidder's payoff because revenues decrease and costs increase.

However, it is possible that the low-valuation bidder's payoffs are either increasing or decreasing in his/her wealth. In either case, greater wealth of the low-valuation bidder leads both contestants to invest more. Larger investments imply that marginal revenues of the low-valuation bidder decrease according to the logit contest success function. ${ }^{14}$

(ii) Greater wealth $W_{2}$ implies that marginal revenues of the low-valuation bidder decrease but are still larger than the constant marginal costs if $R_{2} \sqrt{R_{1}}>2 R_{1} \sqrt{W_{2}}$, that is, for relatively small wealth $W_{2}$. Therefore, the low-valuation bidder's expected payoff increases.

(iii) Greater wealth $W_{2}$ implies that marginal revenues of the low-valuation bidder decrease and become smaller than constant marginal costs if $R_{2} \sqrt{R_{1}}<2 R_{1} \sqrt{W_{2}}$, i.e., for relatively large wealth $W_{2}$. Therefore, the low-valuation bidder's expected payoff decreases. In this case, the low-valuation bidder prefers to have an even tighter constraint. A tighter liquidity constraint can help the low-valuation bidder because the high-valuation bidder reacts by decreasing his/her investment. The low-valuation bidder's expected revenues decrease, but costs decrease even more, such that the lowvaluation bidder's expected payoff increases.

${ }^{13}$ The low-valuation bidder's payoff is positive if $\pi_{2}^{* * *}=R_{2} \sqrt{W_{2}} / \sqrt{R_{1}}-W_{2}>0 \Longleftrightarrow R_{2} \sqrt{R_{1}}>\sqrt{W_{2}} R_{1}$. Because the low-valuation bidder is liquidity-constrained, we know that $R_{2} \sqrt{R_{1}}>\left(R_{1}+R_{2}\right) \sqrt{W_{2}}$. This condition guarantees that the low-valuation bidder's payoff is positive. Because the high-valuation bidder has positive investments, we know that $\sqrt{R_{1}}>\sqrt{W_{2}}$, such that $\pi_{1}^{* * *}$ is also positive.

${ }^{14}$ The intuition is as follows: larger investments $T_{1}$ and $T_{2}$ imply smaller marginal revenues for the low-

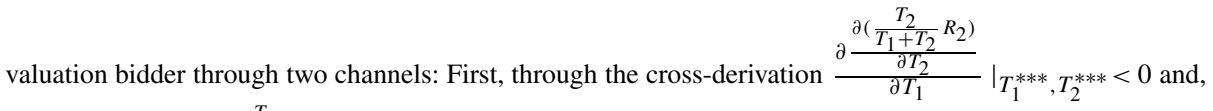
second, through $\left.\frac{\partial \frac{\partial\left(\frac{T_{2}}{T_{1}+T_{2}} R_{2}\right)}{\partial T_{2}}}{\partial T_{2}}\right|_{T_{1}^{* * *}, T_{2}^{* * *}<0}$ 


\subsection{Liquidity constraints for both bidders}

\subsubsection{General cost function}

Suppose that costs are either linear or strictly convex and both contestants are liquidityconstrained. Therefore, each contestant invests his/her entire wealth, such that $T_{1}^{* * * *}=$ $c^{-1}\left(W_{1}\right)$ and $T_{2}^{* * * *}=c^{-1}\left(W_{2}\right)$. We are able to derive Proposition 5:

Proposition 5 If both contestants are liquidity-constrained in equilibrium:

(i) The contestant with the larger wealth invests more.

(ii) Aggregate investments are smaller compared to the case without liquidity constraints.

Proof See Appendix 6.8.

Note that equilibria with two liquidity-constrained contestants only exist within the shaded lenses shown in Figs. $4 \mathrm{a}$ and $\mathrm{b}$. Therefore, the intersections of any two liquidity constraints within these lenses define an equilibrium.

(i) It is obvious that the contestant with greater wealth invests more.

(ii) Aggregate investments are unambiguously smaller compared to the case without constraints, even if the low-valuation bidder potentially increases his/her investment. Thus, the possible increase in investment by the low-valuation bidder never compensates for the high-valuation bidder's investment reduction.

Generally, it is ambiguous whether competitive balance increases or decreases with two liquidity constraints. However, it is easy to see that competitive balance is maximized for symmetric constraints, i.e., $C B=1$.

\subsubsection{Linear costs}

In equilibrium, we get the following payoff for contestant $i$ if costs are linear:

$$
\pi_{i}^{* * * *}=W_{i}\left(\frac{R_{i}}{W_{i}+W_{j}}-1\right) .
$$

Therefore, we are able to provide an additional Proposition 6 for linear costs:

Proposition 6 If both contestants are liquidity-constrained in equilibrium and costs are linear:

(i) The high-valuation bidder's payoff is greater compared to the low-valuation bidder's payoff if the high-valuation bidder's wealth is at least as large as the low-valuation bidder's wealth.

(ii) The high-valuation bidder's payoff is larger than the low-valuation bidder's payoff for $W_{1}\left(R_{1}-W_{1}\right)>W_{2}\left(R_{2}-W_{2}\right)$, if the high-valuation bidder's wealth is smaller than the low-valuation bidder's wealth.

(iii) The high-valuation bidder's payoff is smaller than the low-valuation bidder's payoff for $W_{1}\left(R_{1}-W_{1}\right)<W_{2}\left(R_{2}-W_{2}\right)$ if the high-valuation bidder's wealth is lower than the low-valuation bidder's wealth. 


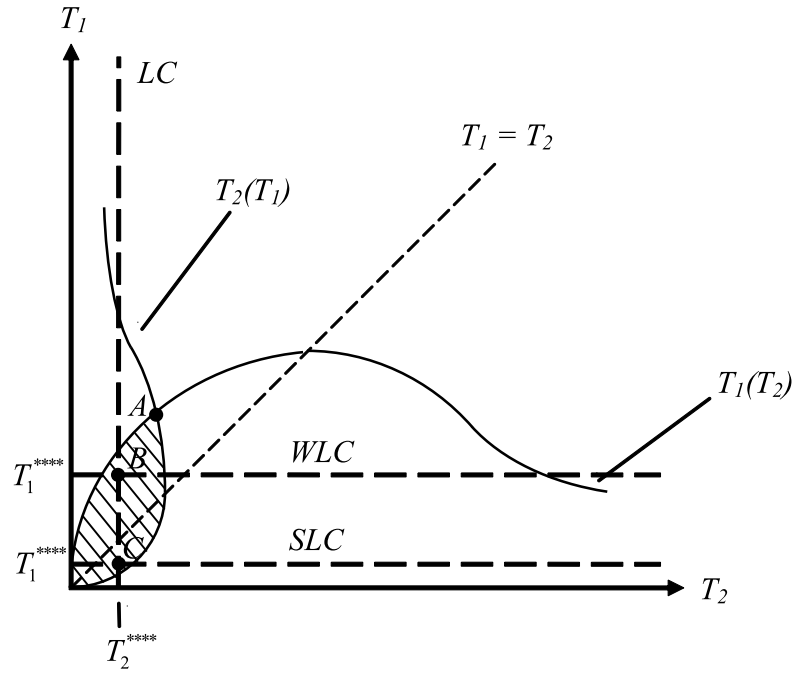

(a)

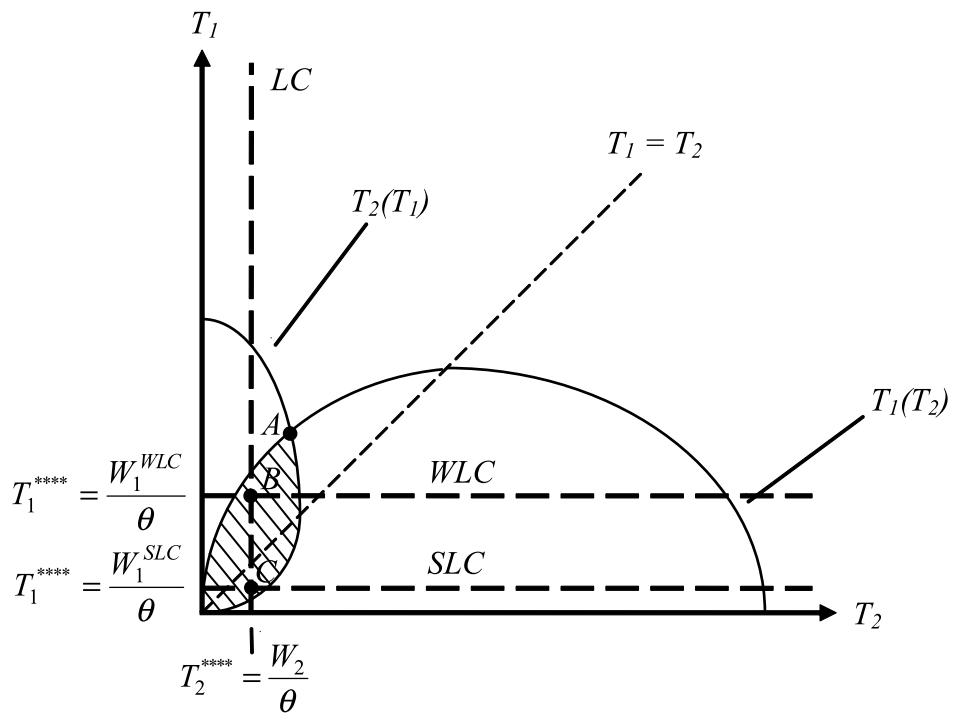

(b)

Fig. 4 a Liquidity constraints for low-val. and high-val. bidder with strictly convex costs. b Liquidity constraints for low-val. and high-val. bidder with linear costs

(i) As long as the high-valuation bidder's wealth is at least as large as the low-valuation bidder's wealth, the high-valuation bidder's payoff is higher, as the high-valuation bidder has a greater prize valuation.

(ii) If the high-valuation bidder has smaller wealth compared to the low-valuation bidder, the high-valuation bidder overcompensates the lower wealth by a higher prize valuation, such that the high-valuation bidder's payoff is larger in equilibrium. This holds for the parameter condition $W_{1}\left(R_{1}-W_{1}\right)>W_{2}\left(R_{2}-W_{2}\right)$. 
(iii) If the high-valuation bidder has smaller wealth compared to the low-valuation bidder, the low-valuation bidder overcompensates the smaller prize valuation by higher investments, such that the low-valuation bidder's payoff is greater in equilibrium. This holds for the parameter condition $W_{1}\left(R_{1}-W_{1}\right)<W_{2}\left(R_{2}-W_{2}\right)$.

\section{Discussion and applications}

In this article, we analyze the optimal investment behavior in contests with asymmetric prize valuations and individual liquidity constraints. We show that aggregate investments will be smaller if at least one contestant is liquidity-constrained. Furthermore, welfare may increase due to the presence of liquidity constraints because of reduced rent-dissipation. This result applies to a large number of contests. Examples include rent-seeking and rent-defending contests, lobbying, standards wars, arms races, litigation, political campaigns, mating contests, conflict, $R \& D$ and patent races, sports tournaments, and competition for market shares. In some industries, such as, pharmaceuticals, firms spend up to $40 \%$ of revenues for marketing activities to increase their market shares (Huck et al. 2002). If these marketing expenditures have no significant effect on overall market size, liquidity constraints will increase overall welfare because they limit unproductive marketing expenditures. Salary caps in professional team sports, limits in arms races, and restrictions on donations to political campaigns have similar effects.

However, liquidity constraints are not always welfare enhancing, even when all contest investments are unproductive. If the high-valuation bidder has a tighter constraint than the low-valuation bidder, the welfare-enhancing reduction of rent-dissipation may be overcompensated by an inefficient prize allocation due to an inefficiently large winning probability of the low-valuation bidder. Consider a standards war in which a big company with deep pockets has an inefficiently high probability of succeeding with an inferior standard against a consortium of smaller competitors with a superior standard.

Furthermore, we show that the effect of liquidity constraints on competitive balance depends on whether the high- or the low-valuation bidder is constrained. If the low-valuation bidder is liquidity-constrained, a greater wealth of the low-valuation bidder will always increase competitive balance. If the high-valuation bidder is constrained, the effect of a larger wealth of the high-valuation bidder on competitive balance depends on the constraint. A strong (weak) liquidity constraint means that the high-valuation bidder has a larger (smaller) winning probability than the low-valuation bidder in equilibrium. We conclude that an increase of the high-valuation bidder's wealth leads to more (less) competitive balance if the high-valuation bidder has a strong (weak) liquidity constraint. This result is important for contests in which value creation does not depend only on the allocation of the prize but also on the level of competitive balance. A typical example is the professional team sports industry. In this industry, contests are designed as championship races. Because value creation by these championship races depends on the level of competitive balance, many leagues have introduced salary caps or similar forms of liquidity constraints. These constraints are usually designed as payroll caps that limit the maximum amount each team can spend on playing talent. If the market shares of teams differ, however, the relationship between value creation and competitive balance is not linear, but rather inversely U-shaped: more value is created if the winning probability of large-market teams increases relative to the winning probability of small-market teams until a maximum is reached. If the winning probability of the large market team increases beyond this threshold, value creation starts to decrease. Leagues with large asymmetries in market size of their teams have introduced exceptions to the salary 
constraints to allow large-market teams to increase their winning probability above 0.5 . Under the so-called Larry Bird rule, for example, the National Basketball Association enables large-market teams to increase their winning probability by allowing teams to exceed the cap when re-signing their star players.

In our view, the most interesting theoretical prediction of our model holds in contests where the low-valuation bidder is liquidity-constrained and costs are linear. In such a contest, a tighter constraint may increase the low-valuation bidder's payoff. The intuition for this counterintuitive result is as follows: a tighter constraint reduces the investment of the lowvaluation bidder. Because investments are strategic complements, the high-valuation bidder will react by reducing his/her investment in equilibrium also. As a result, rent-dissipation decreases and the expected payoffs of both contestants increase. Therefore, liquidity constraints may be surprisingly beneficial for bidders with low valuations. In political campaigns, for example, the "underdog" may benefit from a budget cut because a smaller budget of the constrained low-valuation politician will reduce optimal spending by the highvaluation competitor. Even if this effect may result in a smaller winning probability of the low-valuation politician, both contestants benefit from greater expected payoffs due to lower investment costs.

Acknowledgements Helpful comments by Reto Foellmi, two anonymous referees, the editor, and the participants of the Western Economic Association International (WEAI) conference in Portland (2010) are gratefully acknowledged.

\section{Appendix}

\subsection{Proof of Lemma 1}

Contestant $i$ has the following implicit reactions function for strictly convex costs:

$$
\frac{T_{j}}{\left(T_{i}+T_{j}\right)^{2}} R_{i}=c^{\prime}\left(T_{i}\right)
$$

It is easy to see that $\lim _{T_{j} \rightarrow \infty} T_{i}\left(T_{j}\right)=0$. Therefore, contestant $i$ 's best response is $T_{i}=0$ if contestant $j$ invests infinity. Using the implicit function theorem, we get

$$
\frac{d T_{i}}{d T_{j}}=\frac{R_{i}\left(T_{i}-T_{j}\right)}{2 R_{i} T_{j}+\left(T_{i}+T_{j}\right)^{3} c^{\prime \prime}\left(T_{i}\right)} .
$$

Note that the reaction function is increasing (decreasing) in $T_{j}$ if $T_{i}-T_{j}>0\left(T_{i}-T_{j}<0\right)$. The second derivative of the reaction function yields

$$
\frac{d^{2} T_{i}}{d T_{j}^{2}}=\frac{-2 R_{i}^{2} T_{i}+R_{i}\left(2 T_{j}-4 T_{i}\right)\left(T_{i}+T_{j}\right)^{2} c^{\prime \prime}\left(T_{i}\right)}{\left[2 R_{i} T_{j}\left(T_{i}+T_{j}\right)^{-1}+\left(T_{i}+T_{j}\right)^{2} c^{\prime \prime}\left(T_{i}\right)\right]^{2}} .
$$

Therefore, contestant $i$ 's reaction function is concave if $T_{i}<T_{j}$ because $\frac{d^{2} T_{i}}{d T_{j}^{2}}<0$. If $T_{i}=T_{j}$, then contestant $i$ 's reaction function reaches a maximum because $\frac{d T_{i}}{d T_{j}}=0$ as well as $\left.\frac{d^{2} T_{i}}{d T_{j}^{2}}\right|_{T_{i}=T_{j}}<0$. This maximum is implicitly defined by $R_{i} / 4=T c^{\prime}(T)$. Contestant $i$ 's reaction function has an inflection point if the numerator of $d^{2} T_{i} / d T_{j}^{2}$ equals zero, that is, 
$2 R_{i}^{2} T_{i}=R_{i}\left(2 T_{j}-4 T_{i}\right)\left(T_{i}+T_{j}\right)^{2} c^{\prime \prime}\left(T_{i}\right)$. Note that the reaction function achieves this inflection point after crossing the $45^{\circ}$-line, such that this function becomes convex for even larger $T_{j}$, that is, $\frac{d^{2} T_{i}}{d T_{j}^{2}}>0$.

\subsection{Proof of Lemma 2}

If costs are linear, then the first derivative of $T_{i}\left(T_{j}\right)$ with respect to $T_{j}$ for $0 \leq T_{j} \leq R_{i} / \theta$ yields

$$
\frac{\partial T_{i}\left(T_{j}\right)}{\partial T_{j}}=0.5\left(\frac{T_{j} R_{i}}{\theta}\right)^{-0.5} \frac{R_{i}}{\theta}-1 .
$$

Therefore, we get

$$
\frac{\partial T_{i}\left(T_{j}\right)}{\partial T_{j}} \begin{cases}>0 & \text { if } 0 \leq T_{j}<\frac{R_{i}}{4 \theta}, \\ =0 & \text { if } T_{j}=\frac{R_{i}}{4 \theta}, \\ <0 & \text { if } \frac{R_{i}}{\theta} \geq T_{j}>\frac{R_{i}}{4 \theta} .\end{cases}
$$

The second derivative of the reaction function for $0 \leq T_{j} \leq R_{i} / \theta$ yields

$$
\frac{\partial^{2} T_{i}\left(T_{j}\right)}{\partial T_{j}^{2}}=-0.25\left(\frac{R_{i}}{\theta}\right)^{0.5} T_{j}^{-1.5}<0 .
$$

Therefore, the reaction function $T_{i}\left(T_{j}\right)$ is strictly concave for $0 \leq T_{j} \leq R_{i} / \theta$ and $i=1,2$.

Next, we derive the maximum of the reaction function:

$$
\frac{\partial T_{i}\left(T_{j}\right)}{\partial T_{j}}=0 \quad \Longleftrightarrow \quad T_{j}=\frac{R_{i}}{4 \theta} .
$$

Note that if $\hat{T}_{j}=R_{i} /(4 \theta)$, then $T_{i}\left(\hat{T}_{j}\right)=R_{i} /(4 \theta)$. Therefore, the reaction function $T_{i}\left(T_{j}\right)$ crosses the $45^{\circ}$-line as well as achieves its maximum at point $\left(T_{i}, T_{j}\right)=\left(R_{i} /(4 \theta), R_{i} /(4 \theta)\right)$ for $i=1,2$.

\subsection{Proof of equilibrium with unconstrained bidders}

Strictly convex costs: We have the following condition in equilibrium:

$$
\frac{T_{j}^{*} R_{i}}{T_{i}^{*} R_{j}}=\frac{c^{\prime}\left(T_{i}^{*}\right)}{c^{\prime}\left(T_{j}^{*}\right)} .
$$

Note that the high-valuation bidder invests more in equilibrium. Proof by contradiction: Suppose that $T_{j}^{*} \geq T_{i}^{*}$. Then, the left-hand side of the last equation is larger than one due to $R_{i}>R_{j}$. However, the right-hand side is lower than one because costs are strictly convex. This result is not consistent with the left-hand side. Therefore, $T_{i}^{*}>T_{j}^{*}$ in equilibrium.

The high-valuation bidder has larger expected payoffs in equilibrium. Proof by contradiction: Suppose that $\bar{\pi}_{j} \geq \bar{\pi}_{i}$. Because $T_{i}^{*}>T_{j}^{*}$, contestant $i$ can set $\hat{T}_{i}=T_{j}^{*}$ and will get $\pi_{i}\left(\hat{T}_{i}\right)>\bar{\pi}_{j}$ due to $R_{i}>R_{j}$. Therefore, $\pi_{j} \geq \pi_{i}$ is not consistent within an equilibrium. 
Linear costs: Combining (3), which holds for contestant 1 and 2, and setting $\lambda_{1}=\lambda_{2}=0$ due to the complementary slackness condition, we get

$$
\frac{T_{1}^{*}}{T_{2}^{*}}=\frac{R_{1}}{R_{2}}>1
$$

Therefore, the high-valuation bidder invests more than the low-valuation bidder in equilibrium. Furthermore, dividing contestant 1's payoff by contestant 2's payoff in equilibrium, we get

$$
\frac{\pi_{1}^{*}}{\pi_{2}^{*}}=\left(\frac{R_{1}}{R_{2}}\right)^{3}>1 .
$$

Therefore, the high-valuation bidder has greater expected payoffs than the low-valuation bidder in equilibrium.

\subsection{Proof of Proposition 1}

(i) If only the high-valuation bidder is liquidity-constrained, $\lambda_{1}>0$ and $\lambda_{2}=0$ due to the complementary slackness condition. Then, we get the following two equilibrium conditions:

$$
\begin{aligned}
& W_{1}=c\left(T_{1}\right) \quad \text { and } \\
& \frac{T_{1}}{\left(T_{1}+T_{2}\right)^{2}} R_{2}=c^{\prime}\left(T_{2}\right) .
\end{aligned}
$$

Taking the derivative of $T_{1}$ with respect to $W_{1}$ for the first condition and using the implicit function theorem for the second condition (derivative of $T_{2}$ with respect to $\left.W_{1}\right)$, we get

$$
\frac{d\left(T_{1}^{* *}+T_{2}^{* *}\right)}{d W_{1}}=\frac{\left(c^{-1}\left(W_{1}\right)+T_{2}^{* *}\right) R_{2}+\left(c^{-1}\left(W_{1}\right)+T_{2}^{* *}\right)^{3} c^{\prime \prime}\left(T_{2}^{* *}\right)}{2 c^{-1}\left(W_{1}\right) R_{2}+\left(c^{-1}\left(W_{1}\right)+T_{2}^{* *}\right)^{3} c^{\prime \prime}\left(T_{2}^{* *}\right)} \frac{d c^{-1}\left(W_{1}\right)}{d W_{1}}>0 .
$$

Because $c\left(T_{i}\right)$ is a strictly increasing function, there exists an inverse function $c^{-1}$ which is itself strictly increasing such that $\frac{d c^{-1}\left(W_{1}\right)}{d W_{1}}>0$. Furthermore, $c^{\prime \prime}\left(T_{2}\right)>0$ for a strictly convex cost function or $c^{\prime \prime}\left(T_{2}\right)=0$ for a linear cost function. Therefore, aggregate investments are increasing in $W_{1}$ and therefore, aggregate investments are smaller compared to the case without liquidity constraints.

(ii) Straightforward and therefore omitted.

(iii) Competitive balance $C B=p_{1}\left(T_{1}^{* *}, T_{2}^{* *}\right) / p_{2}\left(T_{1}^{* *}, T_{2}^{* *}\right)$ in equilibrium is given by

$$
\frac{p_{1}\left(T_{1}^{* *}, T_{2}^{* *}\right)}{p_{2}\left(T_{1}^{* *}, T_{2}^{* *}\right)}=\frac{T_{1}^{* *}}{T_{2}^{* *}}=\frac{c^{-1}\left(W_{1}\right)}{T_{2}^{* *}\left(W_{1}\right)}
$$

and affected by a relaxation of the high-valuation bidder's liquidity constraint, that is, an increase in $W_{1}$, as follows:

$$
\frac{\partial\left(\frac{p_{1}\left(T_{1}^{* *}, T_{2}^{* *}\right)}{p_{2}\left(T_{1}^{* *}, T_{2}^{* *}\right)}\right)}{\partial W_{1}}=\frac{\frac{d c^{-1}\left(W_{1}\right)}{d W_{1}} T_{2}^{* *}-c^{-1}\left(W_{1}\right) \frac{d T_{2}}{d W_{1}}}{T_{2}^{* *}} .
$$


Using the implicit function theorem, we get

$$
\frac{d T_{2}}{d W_{1}}=\frac{R_{2}\left(T_{2}^{* *}-c^{-1}\left(W_{1}\right)\right)}{2 c^{-1}\left(W_{1}\right) R_{2}+\left(c^{-1}\left(W_{1}\right)+T_{2}^{* *}\right)^{3} c^{\prime \prime}\left(T_{2}^{* *}\right)} \frac{d c^{-1}\left(W_{1}\right)}{d W_{1}},
$$

and therefore

$$
\begin{aligned}
& \frac{\partial\left(\frac{p_{1}\left(T_{1}^{* *}, T_{2}^{* *}\right)}{p_{2}\left(T_{1}^{* *}, T_{2}^{* *}\right)}\right)}{\partial W_{1}}>0 \\
& \Leftrightarrow \quad\left(T_{2}^{* *}-c^{-1}\left(W_{1}\right) \frac{R_{2}\left(T_{2}^{* *}-c^{-1}\left(W_{1}\right)\right)}{2 c^{-1}\left(W_{1}\right) R_{2}+\left(c^{-1}\left(W_{1}\right)+T_{2}^{* *}\right)^{3} c^{\prime \prime}\left(T_{2}^{* *}\right)}\right) \\
& \quad \times \frac{d c^{-1}\left(W_{1}\right)}{d W_{1}}>0 \\
& \Leftrightarrow \quad c^{-1}\left(W_{1}\right) R_{2} T_{2}^{* *}+\left(c^{-1}\left(W_{1}\right)+T_{2}^{* *}\right)^{3} c^{\prime \prime}\left(T_{2}^{* *}\right) T_{2}^{* *}+R_{2} c^{-1}\left(W_{1}\right)^{2}>0 .
\end{aligned}
$$

The last line is true because $c^{-1}\left(W_{1}\right)$ is positive and $c^{\prime \prime}\left(T_{2}\right) \geq 0$ by assumption.

If there is a weak liquidity constraint, then the high-valuation bidder invests more than the low-valuation bidder in equilibrium, such that $p_{1}\left(T_{1}^{* *}, T_{2}^{* *}\right) / p_{2}\left(T_{1}^{* *}, T_{2}^{* *}\right)>1$. A marginal increase in wealth for the high-valuation bidder leads to less competitive balance (see point $B$ in Figs. $2 \mathrm{a}$ and $\mathrm{b}$ ). However, if there is a strong liquidity constraint, such that the high-valuation bidder invests less than the low-valuation bidder and $p_{1}\left(T_{1}^{* *}, T_{2}^{* *}\right) / p_{2}\left(T_{1}^{* *}, T_{2}^{* *}\right)<1$, then a marginal increase in wealth for the high-valuation bidder leads to more competitive balance (see point $C$ in Figs. 2a and b).

Note that point $B$ and $C$ are stable equilibria, as (given the equilibrium investment $T_{2}^{* *}$ of the low-valuation bidder) the high-valuation bidder would prefer a larger investment, which is not achievable due to his/her constraint. Furthermore, (given the equilibrium investment $T_{1}^{* *}$ of the high-valuation bidder), the low-valuation bidder's investment is lying on his/her reaction function. Therefore, neither the high-valuation bidder nor the low-valuation bidder has an incentive to deviate from these equilibria (point $B$ and $C$ ).

\subsection{Proof of Proposition 2}

If the high-valuation bidder is liquidity-constrained and costs are linear, then a marginal increase in wealth for the high-valuation bidder increases his/her payoff $\pi_{1}^{* *}=$ $\sqrt{W_{1}} R_{1} / \sqrt{R_{2}}-W_{1}$ as follows:

$$
\begin{gathered}
\frac{\partial \pi_{1}^{* *}}{\partial W_{1}}=\frac{0.5 W_{1}^{-\frac{1}{2}}}{\sqrt{R_{2}}} R_{1}-1 \gtreqless 0 \\
\Longleftrightarrow \quad R_{1} \sqrt{R_{2}} \gtreqless 2 R_{2} \sqrt{W_{1}} .
\end{gathered}
$$

Because the high-valuation bidder is liquidity-constrained, we know that

$$
R_{1} \sqrt{R_{2}}>\left(R_{1}+R_{2}\right) \sqrt{W_{1}}
$$

Using the last inequality and comparing it with $\partial \pi_{1}^{* *} / \partial W_{1} \gtreqless 0 \Longleftrightarrow R_{1} \sqrt{R_{2}} \gtreqless 2 R_{2} \sqrt{W_{1}}$, we conclude that $\partial \pi_{1}^{* *} / \partial W_{1}>0$ because $R_{1}>R_{2}$. Therefore, the high-valuation bidder's payoff is increasing in $W_{1}$ if costs are linear. 


\subsection{Proof of Proposition 3}

If only the low-valuation bidder is constrained, then the complementary slackness condition implies $\lambda_{2}>0$ and $\lambda_{1}=0$.

(i) See Proof of Proposition 1(i) changing subscripts. Therefore, if only the low-valuation bidder is liquidity-constrained, then aggregate investments are smaller compared to the case without liquidity constraints.

(ii) Straightforward and therefore omitted.

(iii) Competitive balance $C B=p_{1}\left(T_{1}^{* * *}, T_{2}^{* * *}\right) / p_{2}\left(T_{1}^{* * *}, T_{2}^{* * *}\right)$ in equilibrium is given by

$$
\frac{p_{1}\left(T_{1}^{* * *}, T_{2}^{* * *}\right)}{p_{2}\left(T_{1}^{* * *}, T_{2}^{* * *}\right)}=\frac{T_{1}^{* * *}}{T_{2}^{* * *}}=\frac{T_{1}^{* * *}\left(W_{2}\right)}{c^{-1}\left(W_{2}\right)},
$$

and affected by a relaxation of the low-valuation bidder's liquidity constraint, that is, an increase in $W_{2}$, as follows:

$$
\frac{\partial\left(\frac{p_{1}\left(T_{1}^{* * *}, T_{2}^{* * *}\right)}{p_{2}\left(T_{1}^{* * *}, T_{2}^{* * *}\right)}\right)}{\partial W_{2}}=\frac{\frac{d T_{1}}{d W_{2}} c^{-1}\left(W_{2}\right)-T_{1}^{* * *} \frac{d c^{-1}\left(W_{2}\right)}{d W_{2}}}{c^{-1}\left(W_{2}\right)^{2}} .
$$

Using the implicit function theorem, we get

$$
\frac{d T_{1}}{d W_{2}}=\frac{R_{1}\left(T_{1}^{* * *}-c^{-1}\left(W_{2}\right)\right)}{2 c^{-1}\left(W_{2}\right) R_{1}+\left(c^{-1}\left(W_{2}\right)+T_{1}^{* * *}\right)^{3} c^{\prime \prime}\left(T_{1}^{* * *}\right)} \frac{d c^{-1}\left(W_{2}\right)}{d W_{2}},
$$

and therefore

$$
\begin{aligned}
& \frac{\partial\left(\frac{p_{1}\left(T_{1}^{* * *}, T_{2}^{* * *}\right)}{p_{2}\left(T_{1}^{* * *}, T_{2}^{* * *}\right)}\right)}{\partial W_{2}}<0 \\
& \Leftrightarrow \quad \frac{-c^{-1}\left(W_{2}\right) R_{1} T_{1}^{* * *}-R_{1} c^{-1}\left(W_{2}\right)^{2}-T_{1}^{* * *}\left(c^{-1}\left(W_{2}\right)+T_{1}^{* * *}\right)^{3} c^{\prime \prime}\left(T_{1}^{* * *}\right)}{c^{-1}\left(W_{2}\right)^{2}\left[2 c^{-1}\left(W_{2}\right) R_{1}+\left(c^{-1}\left(W_{2}\right)+T_{1}^{* * *}\right)^{3} c^{\prime \prime}\left(T_{1}^{* * *}\right)\right.} \\
& \quad \times \frac{d c^{-1}\left(W_{2}\right)}{d W_{2}}<0 .
\end{aligned}
$$

The last line is true because $c^{-1}\left(W_{1}\right)$ is positive and $c^{\prime \prime}\left(T_{2}\right) \geq 0$ by assumption. Therefore, a larger $W_{2}$ implies that the high-valuation bidder still invests more than the low-valuation bidder in equilibrium, such that $p_{1}\left(T_{1}^{* * *}, T_{2}^{* * *}\right) / p_{2}\left(T_{1}^{* * *}, T_{2}^{* * *}\right)>1$. But competitive balance increases, that is, $p_{1}\left(T_{1}^{* * *}, T_{2}^{* * *}\right) / p_{2}\left(T_{1}^{* * *}, T_{2}^{* * *}\right)$ decreases because the low-valuation bidder proportionally increases his/her investment more than the high-valuation bidder.

Note that point $B$ is a stable equilibrium in Figs. 3a and b, because (given the equilibrium investment $T_{1}^{* * *}$ of the high-valuation bidder) the low-valuation bidder would prefer a higher investment than $T_{2}^{* * *}$, which is not achievable due to his/her constraint. Furthermore, (given the equilibrium investment $T_{2}^{* * *}$ of the low-valuation bidder), the high-valuation bidder's investment is lying on his/her reaction function. Therefore, neither the high-valuation bidder nor the low-valuation bidder has an incentive to deviate from this equilibrium. 


\subsection{Proof of Proposition 4}

(i) It is easy to see that $\pi_{1}^{* * *}=\left(\sqrt{R_{1}}-\sqrt{W_{2}}\right)^{2}$ is decreasing in $W_{2}$. Note that $\sqrt{R_{1}}>\sqrt{W_{2}}$ because the high-valuation bidder's investments are positive.

If the low-valuation bidder is liquidity-constrained and costs are linear, then a marginal increase in wealth for the low-valuation bidder can increase or decrease his/her payoffs $\pi_{2}^{* * *}=\sqrt{W_{2}} R_{2} / \sqrt{R_{1}}-W_{2}$ :

$$
\begin{gathered}
\frac{\partial \pi_{2}^{* * *}}{\partial W_{2}}=\frac{0.5 W_{2}^{-\frac{1}{2}}}{\sqrt{R_{1}}} R_{2}-1 \gtreqless 0 \\
\Longleftrightarrow \quad R_{2} \sqrt{R_{1}} \gtreqless 2 R_{1} \sqrt{W_{2}} .
\end{gathered}
$$

Because the low-valuation bidder is liquidity-constrained, we know that

$$
R_{2} \sqrt{R_{1}}>\sqrt{W_{2}}\left(R_{1}+R_{2}\right) .
$$

Using the last inequality and comparing it with $\partial \pi_{2}^{* * *} / \partial W_{2} \gtreqless 0 \Longleftrightarrow R_{2} \sqrt{R_{1}} \gtreqless$ $2 R_{1} \sqrt{W_{2}}$, we conclude that

(ii) $\partial \pi_{2}^{* * *} / \partial W_{2}>0$ if $R_{2} \sqrt{R_{1}}>2 R_{1} \sqrt{W_{2}}$.

(iii) However, $\partial \pi_{2}^{* * *} / \partial W_{2}<0$ if $\sqrt{W_{2}}\left(R_{1}+R_{2}\right)<R_{2} \sqrt{R_{1}}<2 R_{1} \sqrt{W_{2}}$ because $R_{1}>R_{2}$ by assumption. Therefore, it is possible that the low-valuation bidder's payoffs are decreasing in $W_{2}$.

\subsection{Proof of Proposition 5}

(i) Suppose that both contestants are liquidity-constrained. Due to the complementary slackness condition, we get $\lambda_{1}>0$ and $\lambda_{2}>0$ and therefore $T_{1}^{* * * *}=c^{-1}\left(W_{1}\right)$ and $T_{2}^{* * * *}=c^{-1}\left(W_{2}\right)$. Then, contestant $i$ invests more than contestant $j$ in equilibrium, if

$$
\begin{gathered}
T_{i}^{* * * *}=c^{-1}\left(W_{i}\right)>c^{-1}\left(W_{j}\right)=T_{j}^{* * * *} \\
\Longleftrightarrow W_{i}>W_{j} .
\end{gathered}
$$

Thus, the contestant with the greater wealth has larger investments in equilibrium.

(ii) According to the proofs of propositions (1) and (3), aggregate investments on the lens boundary and thus also within the lens are smaller compared to the case without liquidity constraints.

\subsection{Proof of Proposition 6}

(i) If the high-valuation bidder's wealth is at least as large as the low-valuation bidder's wealth, then we have the following restrictions, which must hold in equilibrium with two liquidity constraints:

I: $\quad W_{1} \geq W_{2}>0 \quad$ (by assumption)

II: $\quad R_{1}>R_{2}>0 \quad$ (by assumption)

III: $\quad R_{2}>W_{1}+W_{2} \quad$ (required for positive payoffs). 
If these three restrictions hold, it follows that $\pi_{1}^{* * * *}>\pi_{2}^{* * * *} \Longleftrightarrow W_{1}\left(R_{1}-W_{1}\right)>$ $W_{2}\left(R_{2}-W_{2}\right)$. Therefore, if the high-valuation bidder's wealth is at least as large as the low-valuation bidder's wealth, then the high-valuation bidder's payoff is greater compared to the low-valuation bidder's payoff.

(ii) Suppose that $W_{2}>W_{1}>0$. Then, the high-valuation bidder's payoff is larger than the low-valuation bidder's payoff if $\pi_{1}^{* * * *}>\pi_{2}^{* * * *} \Longleftrightarrow W_{1}\left(R_{1}-W_{1}\right)>W_{2}\left(R_{2}-W_{2}\right)$.

(iii) On the other hand, the high-valuation bidder's payoff is smaller than the low-valuation bidder's payoff if $\pi_{1}^{* * * *}<\pi_{2}^{* * * *} \Longleftrightarrow W_{1}\left(R_{1}-W_{1}\right)<W_{2}\left(R_{2}-W_{2}\right)$.

\section{References}

Baik, K. H., \& Kim, I.-G. (1997). Delegation in contests. European Journal of Political Economy, 13(2), 281-298.

Che, Y.-K., \& Gale, I. (1997). Rent dissipation when rent seekers are budget constrained. Public Choice, 92(1), 109-126.

Che, Y.-K., \& Gale, I. (1998a). Standard auctions with financially constrained bidders. Review of Economic Studies, 65(1), 1-21.

Che, Y.-K., \& Gale, I. L. (1998b). Caps on political lobbying. American Economic Review, 88(3), 643-651.

Dasgupta, A., \& Nti, K. O. (1998). Designing an optimal contest. European Journal of Political Economy, 14(4), 587-603.

Dixit, A. (1987). Strategic behavior in contests. American Economic Review, 77(5), 891-898.

Fazzari, S., Hubbard, R. G., \& Petersen, B. (1988a). Investment, financing decisions, and tax policy. American Economic Review, 78(2), 200-205.

Fazzari, S. M., Hubbard, R. G., Petersen, B. C., Blinder, A. S., \& Poterba, J. M. (1988b). Financing constraints and corporate investment. Brookings Papers on Economic Activity, 1988(1), 141-206.

Foellmi, R., \& Oechslin, M. (2010). Market imperfections, wealth inequality, and the distribution of trade gains. Journal of International Economics, 81(1), 15-25.

Gavious, A., Moldovanu, B., \& Sela, A. (2002). Bid costs and endogenous bid caps. Rand Journal of Economics, 33(4), 709-722.

Gross, D., Goidel, R., \& Shields, T. (2002). State campaign finance regulations and electoral competition. American Politics Research, 30(2), 143.

Hubbard, R. G. (1998). Capital-market imperfections and investment. Journal of Economic Literature, 36(1), 193-225.

Huck, S., Konrad, K. A., \& Muller, W. (2002). Merger and collusion in contests. Journal of Institutional and Theoretical Economics, 158(4), 563-575.

Kaplan, T. R., \& Wettstein, D. (2006). Caps on political lobbying: Comment. American Economic Review, 96(4), 1351-1354.

Késenne, S. (2000). The impact of salary caps in professional team sports. Scottish Journal of Political Economy, 47(4), 422-430.

Levitt, S. D. (1994). Using repeat challengers to estimate the effect of campaign spending on election outcomes in the US House. Journal of Political Economy, 102(4), 777-798.

Meirowitz, A. (2008). Electoral contests, incumbency advantages, and campaign finance. The Journal of Politics, 70(03), 681-699.

Milligan, K., \& Rekkas, M. (2008). Campaign spending limits, incumbent spending, and election outcomes. Canadian Journal of Economics/Revue Canadienne d'Économique, 41(4), 1351-1374.

Moldovanu, B., \& Sela, A. (2001). The optimal allocation of prizes in contests. American Economic Review, 91(3), 542-558.

Moldovanu, B., \& Sela, A. (2006). Contest architecture. Journal of Economic Theory, 126(1), 70-96.

Nti, K. O. (1997). Comparative statics of contests and rent-seeking games. International Economic Review, $38(1), 43-59$.

Nti, K. O. (2004). Maximum efforts in contests with asymmetric valuations. European Journal of Political Economy, 20(4), 1059-1066.

Pai, M. M., \& Vohra, R. (2008). Optimal auctions with financially constrained bidders (Working Paper).

Pastine, I., \& Pastine, T. (2010a). Political campaign spending limits (Working Paper).

Pastine, I., \& Pastine, T. (2010b). Politician preferences, law-abiding lobbyists and caps on political contributions. Public Choice, 145, 81-101.

Pitchik, C., \& Schotter, A. (1988). Perfect equilibria in budget-constrained sequential auctions: An experimental study. The Rand Journal of Economics, 19(3), 363-388. 
Stein, W. E., \& Rapoport, A. (2005). Symmetric two-stage contests with budget constraints. Public Choice, 124(3), 309-328.

Szymanski, S., \& Valletti, T. M. (2005). Incentive effects of second prizes. European Journal of Political Economy, 21(2), 467-481.

Tullock, G. (1980). Efficient rent-seeking. In J. Buchanan, R. Tollison, \& G. Tullock (Eds.), Toward a theory of rent seeking society (pp. 97-112). College Station: Texas A\&M University Press.

Yildirim, H. (2005). Contests with multiple rounds. Games and Economic Behavior, 51(1), 213-227. 